\title{
Scientists Deter COYOTES With Toad-Tasting Sheep
}

From Conservation News, Nov. 15, 1972.

There is a researcher at the University of Wisconsin who wants to make a leg of amb taste like a toad.

This same project has researchers elsewhere doing equally strange things, ncluding spraying lambs with cinhamon oil and skunk odor, cougar urine ind Tabasco sauce.

These seemingly-odd though related experiments were recently given top priority in several western states when President Nixon signed a 1972 Executive Order banning the use of redator poisons on public lands. Enironmentalists had increasingly argued hat the poisons were non-selective and vere destroying increasingly-rare and nnocent animals. Livestock men, however, have long complained that vithout the poisons, sheep and cattle osses to predatory coyotes would be lisastrous to the industry.

So researchers are now committed to scientific research for other ways to Hiscourage coyotes from seeking an easy neal of lamb chops. Apparently, common control devices used on other predators, such as bobcats, don't work is well on the coyote. The crafty animal $s$ well-known for his intelligence and idaptability. "If you put a coyote on a ennis court with nothing else in there," aid one veteran trapper "he could hide pehind the ball."

Scientists are first trying to determine exactly how many sheep are actually killed by coyotes and the circumstances nvolved. Although newborn lambs are he most susceptible to predator attack, to one really knows just how many heep are annually killed by coyotes. At wildlife research center in Denver, researchers are conducting tests vith tiny wax-encased electronic sensors pn sheep collars and temperature senitive devices under sheep skins to letermine when a sheep is dead. Supposedly, one will be able to tell whether a coyote killed the sheep or whether the sheep dies of other causes and the coyote merely ate it as carrion.

Other tests are specifically focused on dissuading a coyote from attacking sheep. The toad-tasting experiment is a result of the fact that almost nothing eats toads, particularly coyotes. A certain chemical in the amphibian's skin reportedly produces a disgusting taste. Biochemist Robert McColloch and other University of Wyoming researchers are trying to extract this and similar aversive agents, including the previously-mentioned exotic mixtures, and attach them in capsule form to sheeps' wool. According to Wall Street Journal report of the test: "When bitten by a coyote attacking the sheep, the capsules are supposed to burst, releasing the chemical and giving the coyote a repulsive, sickening taste in his mouth. After that, scientists theorize, the keenwitted coyote will quickly decide to avoid all sheep and teach its young to do the same. Ideally, the scientists hope to create a new generation of coyotes that would shudder at the sight of sheep, which is far from the situation now."

Similar research includes a search by a Colorado State University team for a foul-smelling coyote repellant. Skunk odor or some other revolting smell will be wafted toward coyotes from areas where sheep are. Two South Dakota State University scientists are trying to discourage predators with ultrasonic transmitters implanted in the lead sheep of a flock. These "bleepwhethers" emit a high-pitched sound that, it's hoped, will prove too painful for sensitive coyote ears. However, the pain should prove to be a bit of a problem for the sheep. "We can't drive the sheep herder, dogs, and horses nuts, too," one scientist worried. Other techniques being considered range from mass fencing of rugged sheep ranges to trying to aggressively change the timid, docile nature of sheep. 
Though sheep raisers generally feel that the tests are absolutely necessary, many are suspicious. William Simms, president of the Texas Sheep and Goat Raisers group recently asked: "Who is going to be out there to put this repellant on the lamb when it is born? The mother?"'
But the Interior Department strongl defends predation-control research a "desperately needed." Jack Berryman director of Interior's Wildlife Service Division said that "We can have coyote in abundance and we can protect th sheep industry. We don't have to mak that choice."

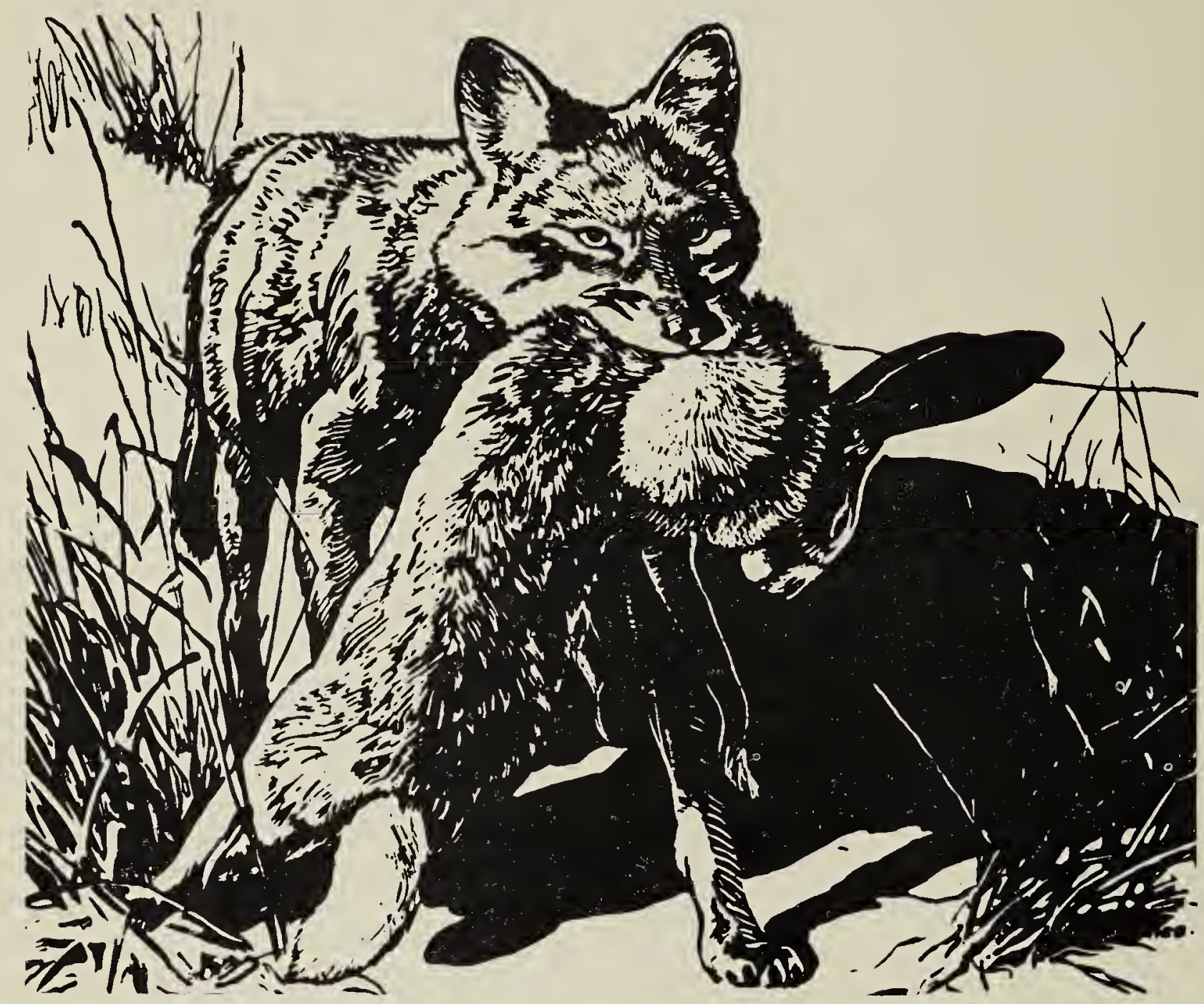

Are you willing to spend an 8-cent stamp for conservation? If so, complete and mail the questionnaire in this issue.

\section{Additional Records of the BULL SNAKE from Alberta}

\section{BY GEORGE B. PENDELBURY*}

It is generally well known that the range of the Bull Snake extends into

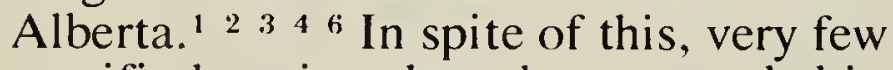
specific locations have been recorded in the literature and the distribution of this snake in the province is yet to be well defined.

The occurrences plotted in Figure 1 are based on several sources of information including (1) published records,

${ }^{*}$ No. 203, 820-5th Ave. S.W. Calgary, Alberta.
(2) specimens in various museums, specimens captured by the writer and $(4$ specimens captured by others an brought to the attention of the writer.

While Bull Snakes are most commo in the southeastern corner of tr province, they are not restricted to th region. The species occurs as far west : Lethbridge and as far north as Hanna The majority of records, however, fa within the range outlined for the speci, by Stebbins." 